\title{
PENENTUAN FREKUENSI PRIBADI BALOK KANTILEVER PADA DIMENSI YANG BERBEDA
}

\author{
Nanang Endriatno \\ Jurusan Teknik Mesin Fakultas Teknik Universitas Halu Oleo, Kendari \\ Nanangendriatno@yahoo.com
}

\begin{abstract}
ABSTRAK
Getaran yang berlebih atau resonansi yang menyebabkan kerusakan pada struktur dapat diantisipasi dalam perencanaan, salah satu caranya adalah mengetahui nilai frekuensi pribadi dari suatu sistem. Tujuan dari penelitian ini adalah untuk menentukan frekuensi pribadi $\left(\omega_{\mathrm{n}}\right)$ dan kekakuan $(k)$ balok aluminium kantilever dengan variasi panjang dan ketebalan balok. Penelitian ini menggunakan metode elemen hingga, balok aluminium yang ditumpu kantilever dibagi menjadi lima elemen dengan berbagai ukuran, lebar balok $5 \mathrm{~cm}$, variasi panjang $25 \mathrm{~cm}, 50 \mathrm{~cm}$, dan $75 \mathrm{~cm}$, variasi ketebalan $0,25 \mathrm{~cm}, 0,5 \mathrm{~cm}$, dan $0,75 \mathrm{~cm}$. Hasil penelitian menunjukkan bahwa posisi elemen, panjang dan ketebalan balok berpengaruh besar terhadap nilai frekuensi pribadi $\left(\omega_{\mathrm{n}}\right)$, kekakuan $(\mathrm{k})$. Nilai frekuensi pribadi berubah pada setiap dimensi balok aluminium dengan nilai maksimum $42746 \mathrm{rad} / \mathrm{s}$ untuk balok $\mathrm{P}=0,25 \mathrm{~m}$ (panjang minimum) dan $\mathrm{T}=$ 0,075 $\mathrm{m}$ (tebal maksimum) pada posisi nodal 1 (dekat tumpuan). Nilai minimum frekuensi pribadi pada $178.1 \mathrm{rad} / \mathrm{s}$ untuk balok $\mathrm{P}=0,75 \mathrm{~m}$ (panjang maksimum), $\mathrm{T}=0,0025 \mathrm{~m}$ (tebal minimum) pada posisi nodal 5 (ujung balok). Nilai kekakuan balok memiliki kecenderungan yang sama dengan frekuensi pribadi dengan nilai tertinggi yaitu $92502 \times 10^{3}$ $\mathrm{kg} / \mathrm{m}$ dan nilai terendah $1610 \mathrm{~kg} / \mathrm{m}$. Hasil ini menunjukkan bahwa semakin tebal balok dan pendek balok maka nilai frekuensi pribadi dan kekakuan meningkat. Posisi elemen dekat tumpuan kantilever juga memiliki frekuensi pribadi dan kekakuan tinggi jika dibandingkan posisi yang jauh dari tumpuan.
\end{abstract}

Kata Kunci : Frekuensi pribadi, Kekakuan, Aluminium, Kantilever

\section{ABSTRACT}

Determination Of The Natural Frequency of Cantilever Beams In Different dimensions. Excessive vibration or resonance that causes damage to the structure can be anticipated in planning, one way is to know the personal frequency value of a system. The purpose of this study is to determine the natural frequency $\left(\omega_{n}\right)$ and stiffness (k) of cantilevered aluminum beams with variations in beam length and thickness. This research used finite element method, cantilevered aluminum beams are divided into five elements of various sizes, beam width of $5 \mathrm{~cm}$, length variations of $25 \mathrm{~cm}, 50 \mathrm{~cm}$ and $75 \mathrm{~cm}$, thickness variations of $0.25 \mathrm{~cm}, 0.5 \mathrm{~cm}$, and $0.75 \mathrm{~cm}$. The results showed that the position of the elements, the length, and thickness of the beam had a big effect on the value of natural frequency ( $\left.\omega_{n}\right)$, stiffness $(k)$. Natural frequency values change in each dimension of the aluminum beam with a maximum value of 42746 $\mathrm{rad} / \mathrm{s}$ for the beam $P=0.25 \mathrm{~m}$ (minimum length) and $T=0.075 \mathrm{~m}$ (maximum thickness) in the nodal 1 position (near the support). The minimum value of natural frequency at $178.1 \mathrm{rad} / \mathrm{s}$ for the beam $P=0.75 \mathrm{~m}$ (maximum length), $T=$ $0.0025 \mathrm{~m}$ (minimum thickness) in nodal position 5 (end of the beam). Beam stiffness value has the same tendency with natural frequency with the highest value that is $92502 \times 103 \mathrm{~kg} / \mathrm{m}$ and the lowest value is $1610 \mathrm{~kg} / \mathrm{m}$. These results indicate that the thicker the beam and the shorter the beam, the value of natural frequency and stiffness increases. The position of the elements near the cantilever support also has a natural frequency and high rigidity when compared to positions that are far from the support.

Keywords: Natural Frequency, Stiffness, Aluminum, Cantilever 


\section{PENDAHULUAN}

Analisis Getaran adalah hal yang penting untuk menghindari kerusakan struktur. Frekuensi pribadi adalah parameter penting untuk karakteristik getaran pada sistem yang merupakan frekuensi alami yang dimiliki suatu sistem saat sistem tersebut dibiarkan bergetar tanpa redaman maupun penggetar [1]. Frekuensi pribadi ini dimiliki oleh setiap sistem, dan perlu untuk diketahui. Suatu sistem tidak boleh digetarkan pada frekuensi yang sama dengan frekuensi pribadinya, karena jika frekuensi penggetar sama dengan frekuensi pribadi maka resonansi terjadi yang ditandai dengan getaran besar pada struktur dan dapat merusak sistem [2].

Model konstruksi dari sistem berpengaruh terhadap nilai frekuensi pribadi [3] [4] [5]. Jenis tumpuan yang digunakan juga menentukan karakteristik getaran yang dihasilkan [3]. Dalam penelitian ini, tumpuan yang digunakan adalah jenis kantilever yang banyak ditemukan dalam struktur bangunan maupun transportasi. Nilai frekuensi pribadi ditentukan dengan metode elemen hingga, terdapat beberapa penelitian yang sudah menggunakan metode ini untuk penentuan frekuensi pribadi [6] [7]. Metode numerik bisanya digunakan untuk menganalisis elemen-elemen dari struktur yang kompleks. Berdasarkan latar belakang diatas, maka tujuan penelitian ini adalah untuk menentukan frekuensi pribadi $\left(\omega_{\mathrm{n}}\right)$ dan kekakuan $(k)$ balok kantilever dengan variasi panjang dan ketebalan balok.

Getaran adalah gerakan periodik secara terus menerus disekitar titik seimbang [8]. Suatu benda bergetar jika memiliki massa dan kekakuan, serta adanya gaya awal yang diberikan atau gaya paksa yang diberikan secara terus menerus. Penurunan rumus frekuensi pribadi, dapat diperoleh dari persamaan diferensial gerak suatu sistem pada sistem getaran bebas tidak teredam [1].

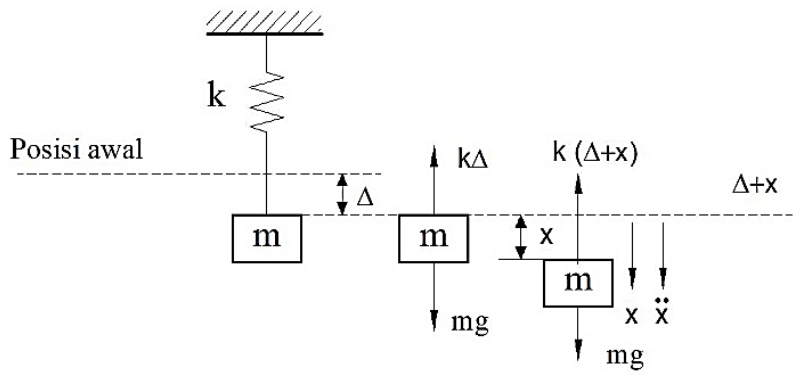

Gambar 1. Sistem pegas.

Gambar 1 menunjukkan pegas yang memiliki massa (m) $(\mathrm{kg})$ dan kekakuan $(\mathrm{k})(\mathrm{N} / \mathrm{m})$. Pada saat diberi massa maka perpindahan pegas terjadsi $(\Delta)$. Pegas diberikan perpidahan awal $(x)$ kemudian dilepas sehingga bergetar pada percepatan $(\ddot{x})\left(\mathrm{m} / \mathrm{s}^{2}\right)$. Berdasarkan gambar 1 dapat ditemukan persamaan diferensial gerak (PDG) untuk mendapatkan frekuensi pribadi :

$$
\begin{aligned}
& F=m . a \Rightarrow k \Delta=m g \\
& m \ddot{x}=-k(\Delta+x)+m g \\
& m \ddot{x}=-k \Delta-K x+k \Delta \\
& k x+m \ddot{x}=0 \\
& \frac{k}{m} x+\ddot{x}=0 \\
& \ddot{x}+k x=0
\end{aligned}
$$

Dari persamaan 1 kemudian dapat dperoleh rumus frekuensi pribadi $\left(\omega_{\mathrm{n}}\right)(\mathrm{rad} / \mathrm{s})[1][9]$.

Metode elemen hingga adalah metode numerik untuk mencari pendekatan penyelesaian permasalahan struktural maupun nonstruktural yang kompleks yang sulit diselesaikan secara analitis. Metode elemen hingga dapat digunakan mencari solusi permasalahan getaran, perpindahan panas, mekanika fluida, konstruksi, dan lainnya. Terdapat beberapa pendekatan dalam metode elemen hingga, 
dalam penelitian ini digunakan pendekatan kekakuan atau metode perpindahan.

Prosedur umum metode elemen hingga adalah menentukan elemen lokal, lalu mencari solusi pada tiap elemen-elemen, selanjutnya menggabungkan penyelesaian dari tiap-tiap elemen, memasukkan syarat batas atau kondisi yang diberikan sehingga dapat dicari solusi umum dari permasalahan tersebut [10].

\section{METODE}

\section{Metode Penelitian}

Penelitian dilakukan dengan metode numerik di Laboratorium Desain dan Konstruksi Jurusan Teknik Mesin Universitas Halu Oleo. Perhitungan frekuensi pribadi dan kekakuan balok kantilever aluminium dianalisis dengan menggunakan metode elemen hingga. Peralatan yang digunakan dalam penelitian terdiri adalah komputer Intel Pentium Core $i 7$ untuk pehitungan frekuensi pribadi secara numerik.

Diketahui data awal sebagai berikut:

- Modulus elastis aluminium $=7 \times 10^{10} \mathrm{~N} / \mathrm{m}^{2}$ [13].

- Densitas Aluminium $=2700 \mathrm{~kg} / \mathrm{m}^{3}[13]$

- Jumlah bagian struktur (je) $=5$

- Panjang total $(\mathrm{L})=0,25 \mathrm{~m}, 0,5 \mathrm{~m}$, dan $0,75 \mathrm{~m}$

- $\quad$ Lebar total (b) $=0,05 \mathrm{~m}$

- Tebal total $(\mathrm{t})=0,0025 \mathrm{~m}, 0.005 \mathrm{~m}$, dan 0,0075 $\mathrm{m}$

\section{Prosedur Penentuan Frekuensi Pribadi}

Langkah-langkah perhitungan frekuensi pribadi adalah seperti dibawah ini:

1. Membagi elemen balok kantilever, selanjutnya menentukan jumlah titik tiap bagian, dan derajat kebebasan.

Dalam perhitugan ini struktur dianalisis dalam 5 elemen, jumlah total titik nodalnya 6 , dengan 12 derajat kebebasan, seperti pada gambar 3 .

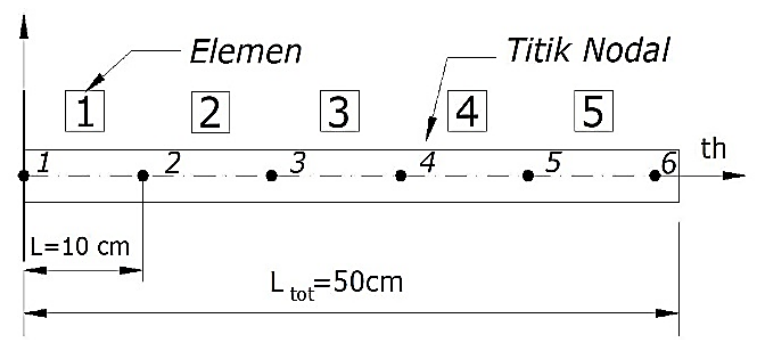

Gambar 3. Diagram benda bebas dari balok kantilver

2. Menentukan Rumus matriks kekakuan dan massa tiap elemen.

Karena metode elemen hingga yang digunakan melalui pendekatan metode kekakuan [1], maka Matriks massa lokal dihitung dengan rumus (2) :

$$
[m]=\frac{m l}{420}\left[\begin{array}{cccc}
156 & 22 l & 54 & -13 l \\
22 l & 4 l^{2} & 13 l & -3 l^{2} \\
54 & 13 l & 156 & -22 l \\
-13 l & -3 l^{2} & -22 l & 4 l^{2}
\end{array}\right]
$$

Untuk matriks kekakuan lokal dihitung dengan persamaan (3), dimana $\mathrm{E}$ adalah modulus elastis $\left(\mathrm{Kg} / \mathrm{m}^{2}\right)$, sedangkan I adalah momen inersia (I) $\left(\mathrm{m}^{4}\right)$ :

$$
[k]=\frac{E I}{l^{3}}\left[\begin{array}{cccc}
12 & 6 l & -12 & 6 l \\
6 l & 4 l^{2} & -6 l & 2 l^{2} \\
-12 & -6 l & 12 & -6 l \\
6 l & 2 l^{2} & -6 l & 4 l^{2}
\end{array}\right]
$$

momen inersia $\left(\mathrm{m}^{3}\right)$ balok dihitung dengan rumus (4), dimana $\mathrm{b}$ adalah lebar balok (m), $\mathrm{h}$ adalah tebal balok $(\mathrm{m})$ :

$$
I=\frac{b h^{3}}{12}
$$

3. Setelah matriks massa dan kekakuan dihitung pada tiap elemen, langkah selanjutnya mentransfer matriks tersebut dari koordinat lokal kekoordinat global sesuai dengan posisi nodalnya.

4. Menentukan kondisi batas pada sistem, dimana untuk tumpuan kantilever perindahan linear $\left(\mathrm{v}_{1}\right)$ dan sudut $\left(\theta_{1}\right)$ pada titik nodal 1 adalah nol sehingga

5. Menentukan frekuensi pribadi $\left(\omega_{\mathrm{n}}\right)$ dengan menggunakan persamaan (5), 


$$
\omega_{n}=\sqrt{[\cdot \bar{M}]^{-1}[\bar{K}]}
$$

Prosedur diatas adalah prosedur umum dalam metode elemen hingga [10] dan karena proses perhitungannya panjang maka tidak memungkinkan untuk ditampilkan semua didalam jurnal ini. Prosedur penelitian diatas telah dilakukan sebelumnya oleh peneliti yang sama baik secara numerik maupun ekserimen dan hasil yang diperoleh tidak berbeda jauh [6] [11] [12], dalam penelitian tersebut lebih difokuskan pada nilai frekuensi pribadi balok komposit dengan dimensi yang sama.

\section{HASIL DAN PEMBAHASAN}

Hasil analisa frekuensi pribadi dan kekakuan yang didapat dengan menggunakan metode elemen hingga dari balok kantilever aluminium dapat di lihat pada Tabel 1 .

Tabel 1. Data dimensi dan massa balok kantilver Aluminium

\begin{tabular}{cccccc}
\hline $\begin{array}{c}\text { Panjang } \\
(\mathrm{m})\end{array}$ & $\begin{array}{c}\text { Lebar } \\
(\mathrm{m})\end{array}$ & $\begin{array}{c}\text { Tebal } \\
(\mathrm{m})\end{array}$ & $\begin{array}{c}\text { Volume } \\
\left(\mathrm{m}^{3}\right)\end{array}$ & $\begin{array}{c}\text { Densitas } \\
\left(\mathrm{kg} / \mathrm{m}^{3}\right)\end{array}$ & $\begin{array}{c}\text { Massa } \\
(\mathrm{kg})\end{array}$ \\
\hline 0.25 & 0.05 & 0.0025 & 0.00003125 & 2700 & 0.084 \\
0.5 & 0.05 & 0.0025 & 0.0000625 & 2700 & 0.169 \\
0.75 & 0.05 & 0.0025 & 0.00009375 & 2700 & 0.253 \\
\hline 0.25 & 0.05 & 0.005 & 0.0000625 & 2700 & 0.169 \\
0.5 & 0.05 & 0.005 & 0.000125 & 2700 & 0.338 \\
0.75 & 0.05 & 0.005 & 0.0001875 & 2700 & 0.506 \\
\hline 0.25 & 0.05 & 0.0075 & 0.00009375 & 2700 & 0.253 \\
0.5 & 0.05 & 0.0075 & 0.0001875 & 2700 & 0.506 \\
0.75 & 0.05 & 0.0075 & 0.00028125 & 2700 & 0.759 \\
\hline
\end{tabular}

Tabel 2. Hasil Perhitungan Frekuensi Pribadi pada berbagai dimensi balok kantilever Aluminium

\begin{tabular}{ccccccc}
\hline $\begin{array}{c}\text { Panjang } \\
(\mathrm{m})\end{array}$ & $\begin{array}{c}\text { Tebal } \\
(\mathrm{m})\end{array}$ & $\begin{array}{c}\varpi_{1} \\
(\mathrm{rad} / \mathrm{s})\end{array}$ & $\begin{array}{c}\varpi_{2} \\
(\mathrm{rad} / \mathrm{s})\end{array}$ & $\begin{array}{c}\varpi_{3} \\
(\mathrm{rad} / \mathrm{s})\end{array}$ & $\begin{array}{c}\varpi_{4} \\
(\mathrm{rad} / \mathrm{s})\end{array}$ & $\begin{array}{c}\varpi_{5} \\
(\mathrm{rad} / \mathrm{s})\end{array}$ \\
\hline 0.25 & 0.0025 & 14249 & 11796 & 8355 & 4890 & 1603 \\
0.5 & 0.0025 & 3562.1 & 2948.9 & 2088.7 & 1222.4 & 400.8 \\
0.75 & 0.0025 & 1583.2 & 1310.6 & 928.3 & 543.3 & 178.1 \\
\hline 0.25 & 0.005 & 28497 & 23591 & 16709 & 9779 & 3206 \\
0.5 & 0.005 & 7124.3 & 5897.8 & 4177.3 & 2444.8 & 801.6 \\
0.75 & 0.005 & 3166.4 & 2621.3 & 1856.6 & 1086.6 & 356.3 \\
\hline 0.25 & 0.0075 & 42746 & 35387 & 25064 & 14669 & 4810
\end{tabular}

\begin{tabular}{ccccccc}
0.5 & 0.0075 & 10686 & 8847 & 6266 & 3667 & 1202 \\
0.75 & 0.0075 & 4749.5 & 3931.9 & 2784.9 & 1629.9 & 534.4 \\
\hline
\end{tabular}

Tabel 3. Hasil Perhitungan Kekakuan pada berbagai dimensi balok kantilever Aluminium

\begin{tabular}{ccccccc}
\hline $\begin{array}{c}\text { Panjang } \\
(\mathrm{m})\end{array}$ & $\begin{array}{c}\text { Tebal } \\
(\mathrm{m})\end{array}$ & $\begin{array}{c}\mathrm{K}_{1} \\
(\mathrm{~kg} / \mathrm{m})\end{array}$ & $\begin{array}{c}\mathrm{K}_{2} \\
(\mathrm{~kg} / \mathrm{m})\end{array}$ & $\begin{array}{c}\mathrm{K}_{3} \\
(\mathrm{~kg} / \mathrm{m})\end{array}$ & $\begin{array}{c}\mathrm{K}_{4} \\
(\mathrm{~kg} / \mathrm{m})\end{array}$ & $\begin{array}{c}\mathrm{K}_{5} \\
(\mathrm{~kg} / \mathrm{m})\end{array}$ \\
\hline 0.25 & 0.0025 & 3426000 & 2348000 & 1177900 & 403500 & 43400 \\
0.5 & 0.0025 & 428250 & 293490 & 147240 & 50430 & 5420 \\
0.75 & 0.0025 & 126890 & 86960 & 43630 & 14940 & 1610 \\
\hline 0.25 & 0.005 & 27408000 & 18784000 & 9423000 & 3228000 & 347000 \\
0.5 & 0.005 & 3426000 & 2348000 & 1177900 & 403500 & 43400 \\
0.75 & 0.005 & 1015100 & 695700 & 349000 & 119500 & 12900 \\
\hline 0.25 & 0.0075 & 92502000 & 63395000 & 31803000 & 10893000 & 1171000 \\
0.5 & 0.0075 & 11563000 & 7924000 & 3975000 & 1362000 & 146000 \\
0.75 & 0.0075 & 3426000 & 2348000 & 1177900 & 403500 & 43400 \\
\hline
\end{tabular}

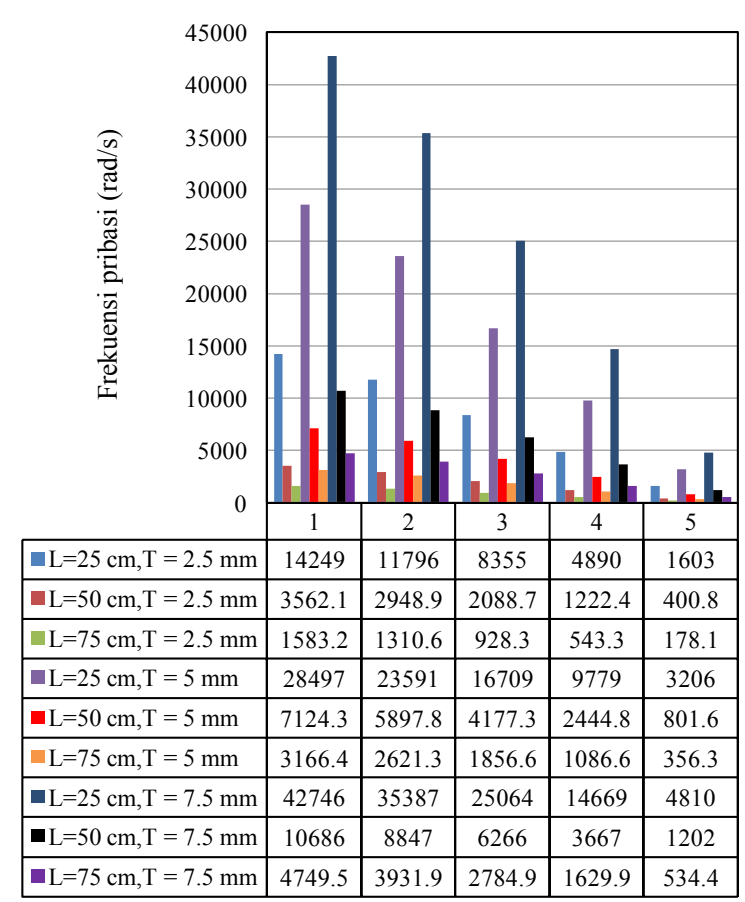

Grafik 1. Hubungan frekuensi pribadi vs posisi elemen pada berbagai dimensi aluminium 


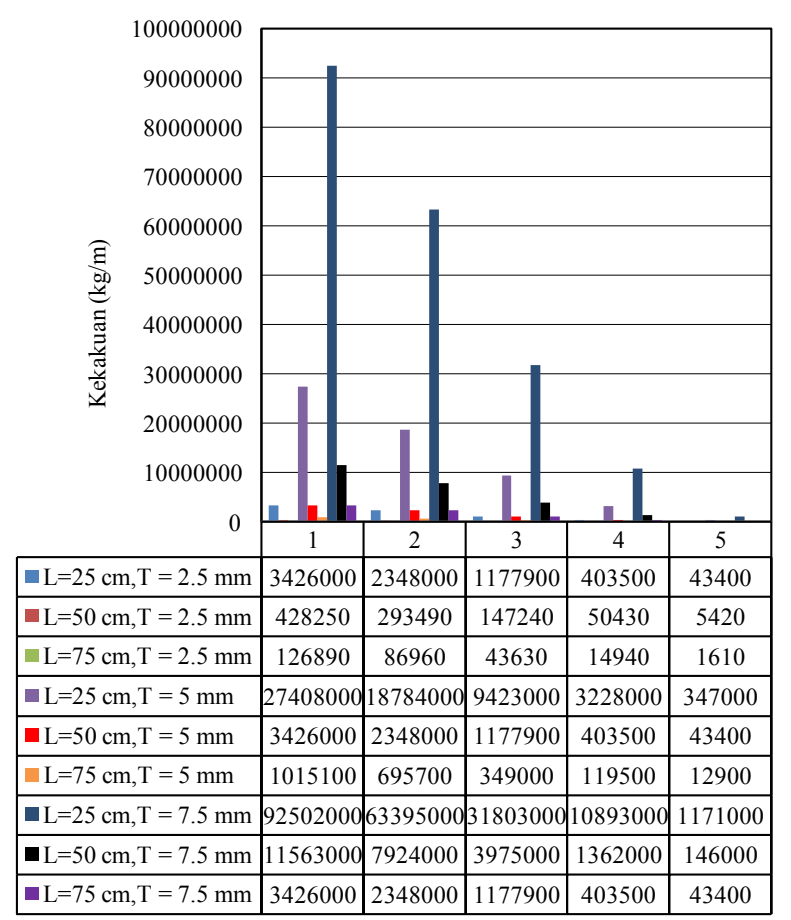

Grafik 2. Hubungan kekakuan vs posisi elemen pada berbagai dimensi aluminium

Tabel 1 dan grafik 1 menujukkan nilai frekuensi pribadi pada balok kantilever aluminium dimana nilainya berubah setiap perubahan dimensi balok Nilai tertinggi $42746 \mathrm{rad} / \mathrm{s}$ pada balok $\mathrm{P}=0,25 \mathrm{~m}$ dan $\mathrm{T}=0,075 \mathrm{~m}$ atau pada balok dengan panjang terendah dan ketebalan tertinggi serta pada posisi nodal 1 (dekat tumpuan). Sedangan terendah pada $178.1 \mathrm{rad} / \mathrm{s}$ pada balok $\mathrm{P}=0,75 \mathrm{~m}, \mathrm{~T}=0,0025 \mathrm{~m}$ atau pada balok dengan panjang tertinggi dan ketebalan terendah, serta pada posisi nodal 5 (ujung balok). Tabel 2 dan grafik 2 menunjukkan nilai kekakuan balok memiliki kecenderungan yang sama dengan frekuensi pribadi [6] [12] [11] [7] dengan nilai tertinggi yaitu $92502 \times 10^{3} \mathrm{~kg} / \mathrm{m}$ dan nilai terendah $1610 \mathrm{~kg} / \mathrm{m}$. Peningkatan frekuensi pribadi berbanding lurus dengan kekakuan, ketika balok dengan panjang yang pendek dan posisi dekat tumpuan serta memiliki ketebalan tinggi cenderung mampu untuk mempertahankan posisinya terhadap getaran atau dengan kata lain dibutuhkan getaran atau frekuensi yang tinggi untuk menggetarkan elemen tersebut. Frekuensi pribadi berhubungan dengan ambang batas getaran dari sistem dimana sistem tidak boleh digetarkan pada frekuensi tersebut.

\section{KESIMPULAN}

Dari penelitian ini dapat disimpulkan bahwa nilai Frekuensi pribadi balok kantilever aluminium tertinggi pada balok dengan panjang terkecil dan ketebalan tertinggi serta pada posisi nodal 1 (dekat tumpuan) dengan nilai frekuensi pribadi $42746 \mathrm{rad} / \mathrm{s}$ dan terendah pada balok dengan panjang terbesar dan ketebalan terendah serta pada posisi nodal 5 (ujung balok) dengan frekuensi pribadi $178.1 \mathrm{rad} / \mathrm{s}$. Kekakuan balok kantilever aluminium memiliki kecenderungan yang sama dengan frekuensi pribadi dimana tertinggi dengan nilai $92502 \times 10^{3} \mathrm{~kg} / \mathrm{m}$ dan terendah dengan nilai $1610 \mathrm{~kg} / \mathrm{m}$

\section{DAFTAR PUSTAKA}

[1] K. S. Graham, Fundamentals of Mechanical Vibrations, United states of America: McGraw-Hill, Inc., 1996.

[2] L. Son, M. Bur and M. Rusli, "Pengaruh Profil dan Dimensi Penampang Kolom terhadap Harga Frekuensi Pribadi dan Bentuk Modus Getar Struktur Bangunan Dua Lantai," in Prosiding SNTTM XVI, Surabaya, 2017.

[3] Naharuddin, "Pengaruh Jenis Tumpuan terhadap Frekuensi Pribadi pada Getaran Balok Lentur," Jurnal Ilmiah Matematika Terapan ISSN : 2540-766X, Vols. Vol. 6, No. 1, pp. 6874, 2009.

[4] A. Yanto, "Analisa Unjuk Kerja Pengayak Getar Sebagai Sistem Getaran Dua Derajat Kebebasan terhadap Pengayakan Abu Sekam Padi," Jurnal Momentum ISSN : 1693-752X, vol. Vol. 15 No. 2, pp. 125-129, 2013.

[5] L. Son and R. Afandi, "Analisis Frekuensi Pribadi Dan Modus Getar Struktur Pesawat 
Tanpa Awak Tipe Flying Wings," Jurnal Sistem Mekanik dan Termal ISSN : 2597-4483, Vols. Vol. 02, No. 02, pp. 36-42, 2018.

[6] N. Endriatno, "Metode Elemen Hingga Untuk Analisis Numerik Pengaruh Variasi Arah Serat Terhadap Getaran Balok Komposit Serat Abaca Bermatriks Epoksi," Dinamika Jurnal Ilmiah Teknik Mesin ISSN: 2085-8817, Vols. Vol. 4, No. 2 Mei, pp. 39-46, 2013.

[7] Mustafa, "Penentuan Frekuensi Pribadi pada Getaran Balok Komposit dengan Penguat Fiberglass," Jurnal Mekanikal, Vols. Vol. 2 No. 2 ISSN : 2086-3403, pp. 163-168, 2011.

[8] A. Hamid, Praktikal Vibrasi Mekanik Teori dan Praktik, Yogyakarta: Graha Ilmu, 2012.

[9] K. J. M, Mechanical Vibration, Department of Mechanical and Manufacturing Engineering: The University of Melbourne, 2008.

[10] L. D. Logan, A First Course in the Finite Element Method, University of WisconsinPlatteville: Thomson, 2007.

[11] N. Endriatno and Y. Gunawan, "Kaji Eksperimental Getaran Balok Komposit yang diperkuat Serat Ijuk," Dinamika Jurnal Ilmiah Teknik Mesin ISSN: 2085-8817, Vols. Vol. 4, No. 1, pp. 45-51, 2012.

[12] Y. Gunawan and N. Endriatno, "Kaji Eksperimental Getaran Balok Komposit yang diperkuat Serat Abaca," Dinamika Jurnal Ilmiah Teknik Mesin ISSN: 2085-8817, Vols. Vo. 3, No. 2, pp. 189-194, 2012.

[13] R. S. Khurmi, Strength of materials, New Delhi: S. Chand and Company LTD, 2008. 